J.Y. PARK

KODAI MATH. J.

11 (1988), $8-16$

\title{
ASYMPTOTIC BEHAVIOR OF PERIODIC SOLUTIONS IN BANACH SPACE
}

\author{
By JONG YEOUL PARK
}

\section{Introduction.}

We consider the following problem:

$$
\begin{aligned}
& \frac{d u(t)}{d t}+A u(t) \ni f(t), \quad t \in(0, \infty), \\
& u(0)=x,
\end{aligned}
$$

where $A$ is an $m$-accretive operator in Banach space $X$ and $f \in L_{1 \mathrm{loc}}^{1}(0, \infty ; X)$ is $T$-periodic. Let $\left\{C_{t}\right\}_{t \geq 0}$ be a nonempty closed convex subset of a Banach space and let $U=\{U(t, s): 0 \geqq s \geqq t\}$ be a nonexpansive operator constrained in $\left\{C_{t}\right\}$, i. e., $U$ is a family of mappings $U(t, s): C_{s} \rightarrow C_{t}$ such that

$$
\begin{aligned}
& U(t, s) U(s, r)=U(t, r), \quad U(r, r)=I, \\
& |U(t, s) x-U(t, s) y| \leqq|x-y|
\end{aligned}
$$

for all $0 \leqq r \leqq s \leqq t$ and $x, y \in C_{s}$. Such an evolution operator $U$ is said to be $T$-periodic $(T>0)$ if

$$
C_{t+T}=C_{t} \text { and } \quad U(t+T, s+T)=U(t, s)
$$

for all $0 \leqq s \leqq t$. Then, a function $u:[0, \infty) \rightarrow X$ is an almost semitrajectory of $U$ if

$$
\lim _{s \rightarrow \infty} \sup _{t \geq s}|u(t)-U(t, s) u(s)|=0 .
$$

In what follows, let $U=\{U(t, s): 0 \leqq s \leqq t\}$ be a $T$-periodic nonexpansive evolution operator constrained in $\left\{C_{t}\right\}$ and we take $u(t)=U(t, 0) u(0)$ for $t \geqq 0$. We shall denote $u(n T+t)$ by $u_{n}(t)$.

If $F\left(U_{t}\right)=\{x: U(T+t, t) x=x$ for $0 \leqq t \leqq T\}$ is nonempty, then we can take $z \in F\left(U_{t}\right)$, and we see that

$$
\lim _{n \rightarrow \infty}\left|u_{n}(t)-z\right|=\rho(t)
$$

exists. It is well known [1] that (1) has a unique integral solution $U(t ; s, x)$

Received June 19, 1987 
whenever $x \in \overline{D(A)}$ and by setting $U(t, s) x=U(t ; s, x)$, we see that $\{U(t, s): 0$ $\leqq s \leqq t\}$ forms a $T$-periodic nonexpansive evolution operation operator constrained in $\left\{C_{t}\right\}$.

The present paper is concerned with the asymptotic behavior of the $T$ periodic integral solution of (1). We prove that if $u$ is an almost semitrajectory of $U$ and $u_{n}(t)=u(n T+t)$, then the closed convex set

$$
\bigcap_{k} \overline{c o}\left\{u_{n}(t): n \leqq k\right\} \cap F\left(U_{t}\right)
$$

consists of at most one point, where $\overline{c o}\left\{u_{n}(t): n \geqq k\right\}$ is the closed convex hull of $\left\{u_{n}(t): n \geqq k\right\}$. This result is applied to study the problem of weak convergence of the sequence $\left\{u_{n}(t): n \geqq 0\right\}$. We also prove that if $P$ is the metric projection of $X$ onto $F\left(U_{t}\right)$, then the strong $\lim _{n \rightarrow \infty} P u_{n}(t)$ exists. Our proofs employ the methods of Lau-Takahashi [6] and W. Takahashi-J. Y. Park [7].

\section{Lemmas.}

LEMma 1. Let $X$ be a uniformly convex Banach space with a Fréchet differentiable norm and $u$ is an almost semitrajectory of $U$. Let

$$
F\left(U_{t}\right) \neq \phi, y \in F\left(U_{t}\right), 0<\alpha \leqq \beta<1 \text { and } r=\lim _{n \rightarrow \infty}\left|u_{n}(t)-y\right| .
$$

Then, for any $\varepsilon>0$, there exists $n_{0} \geqq 0$ such that

$$
\left|U(m T+t, t)\left(\lambda u_{n}(t)+\delta(1-\lambda) y\right)-\left(\lambda U(m T+t, t) u_{n}(t)+(1-\lambda) y\right)\right|<\varepsilon
$$

for all $n \geqq n_{0}, m \geqq 0$ and $\lambda \in R$ with $\alpha \leqq \lambda \leqq \beta$.

Proof. Let $r>0$. Then we can choose $d>0$ so small that

$$
(r+d)\left(1-c \delta\left(\frac{\varepsilon}{r+d}\right)\right)=r_{0}<r
$$

where $\delta$ is the modulus of convexity of the norm and

$$
c=\min \{2 \lambda(1-\lambda): \alpha \leqq \lambda \leqq \beta\} .
$$

Let $a>0$ with $r_{0}+2 a<r$. Then we can choose $n_{0} \geqq 0$ such that

$$
\left|u_{n}(t)-y\right| \geqq r-a \text { and }\left|u_{m+n}(t)-U(m T+t, t) u_{n}(t)\right|<a
$$

for all $n \geqq n_{0}$ and $m \geqq 0$ because $u$ is an almost semitrajectory of $U$. Suppose that

$$
\mid U(m T+t, t)\left(\lambda u_{n}(t)+(1-\lambda) y\right)-\left(\lambda U(m T+t, t) u_{n}(t)+(1-\lambda) y \mid \geqq \varepsilon\right.
$$

for some $n \geqq n_{0}, m \geqq 0$ and $\lambda \in R$ with $\alpha \leqq \lambda \leqq \beta$. Put $u=(1-\lambda)(U(m T+t, t) z-y)$ and $v=\lambda\left(U(m T+t, t) u_{n}(t)-U(m T+t, t) z\right)$, where $z=\lambda u_{n}(t)+(1-\lambda) y$. Then $|u| \leqq$ $\lambda(1-\lambda)\left|u_{n}(t)-y\right|$ and $|v| \leqq \lambda\left|u_{n}(t)-z\right|=\lambda(1-\lambda)\left|u_{n}(t)-y\right|$. We also have that 
and

$$
|u-v|=\mid U(m T+t, t) z-\left(\lambda U(m T+t, t) u_{n}(t)+(1-\lambda) y \mid \geqq \varepsilon\right.
$$

$$
\lambda u+(1-\lambda) v=\lambda(1-\lambda)\left(U(m T+t, t) u_{n}(t)-y\right) .
$$

So by using the Lemma in [5], we have

$$
\begin{aligned}
& \lambda(1-\lambda)\left|U(m T+t, t) u_{n}(t)-y\right|=|\lambda u+(1-\lambda) v| \\
& \leqq \lambda(1-\lambda)\left|u_{n}(t)-y\right|\left(1-2 \lambda(1-\lambda) \delta\left(\frac{\varepsilon}{\left|u_{n}(t)-y\right|}\right)\right) \\
& \leqq \lambda(1-\lambda)(r+d)\left(1-c \delta\left(\frac{\varepsilon}{r+d}\right)\right) \\
&=\lambda(1-\lambda) r_{0}
\end{aligned}
$$

and hence $\left|U(m T+t, t) u_{n}(t)-y\right| \leqq r_{0}$. This implies

$$
\begin{aligned}
\left|u_{n+m}(t)-y\right| & \leqq\left|u_{n+m}(t)-U(m T+t, t) u_{n}(t)\right|+\left|U(m T+t, t) u_{n}(t)-y\right| \\
& \leqq a+r_{0}<r-a .
\end{aligned}
$$

On the other hand, $\left|u_{n}(t)-y\right| \geqq r-a$ for all $n \geqq n_{0}$, this is a contradiction. In the case when $r=0$, let $y \in F\left(U_{t}\right)$ and $\lambda \in R$ with $0 \leqq \lambda \leqq 1$,

$$
\begin{aligned}
&\left|U(m T+t, t)\left(\lambda u_{n}(t)+(1-\lambda) y\right)-\left(\lambda U(m T+t, t) u_{n}(t)+(1-\lambda) y\right)\right| \\
& \leqq \lambda\left|U(m T+t, t)\left(\lambda u_{n}(t)+(1-\lambda) y\right)-U(m T+t, t) u_{n}(t)\right| \\
& \quad+(1-\lambda)\left|U(m T+t, t)\left(\lambda u_{n}(t)+(1-\lambda) y\right)-y\right| \\
& \leqq \lambda\left|\lambda u_{n}(t)+(1-\lambda) y-u_{n}(t)\right|+(1-\lambda)\left|\lambda u_{n}(t)+(1-\lambda) y-y\right| \\
& \leqq 2 \lambda(1-\lambda)\left|u_{n}(t)-y\right| .
\end{aligned}
$$

So, we obtain the desired result.

Let $x$ and $y$ be element of $X$, then we denote by $[x, y]$ the set $\{\lambda x+$ $(1-\lambda) y: 0 \leqq \lambda \leqq 1\}$.

LEMMA 2 [6]. Let $C$ be a closed convex subset of a uniformly convex Banach space $X$ with a Fréchet differentiable norm and $\left\{x_{\alpha}\right\}$ a bounded set in $C$. Let $z \in \bigcap_{\beta} \overline{c o}\left\{x_{\alpha}: \alpha \geqq \beta\right\}, y \in C$ and $\left\{y_{\alpha}\right\}$ a net of element in $C$ with $y_{\alpha} \in\left[y, x_{\alpha}\right]$ and

$$
\left|y_{\alpha}-z\right|=\min \left\{|u-z|: u \in\left[y, x_{\alpha}\right]\right\} \text {. }
$$

If $y_{\alpha} \rightarrow y$, then $y=z$.

Lemma 3. Let $X$ be a uniformly convex Banach space with a Fréchet differentiable norm and $u$ is an almost semitrajectory of $U$. Let $F\left(U_{t}\right) \neq \phi$,

$$
z \in \bigcap_{k} \overline{c o}\left\{u_{n}(t): n \geqq k\right\} \cap F\left(U_{t}\right)
$$


and $y \in F\left(U_{t}\right)$. Then, for any $\varepsilon>0$, there is $n_{0} \geqq 0$ such that

for all $n \geqq n_{0}$.

$$
\left\langle u_{n}(t)-y, J(y-z)\right\rangle \leqq \varepsilon|y-z|
$$

Proof. Let $z \in \bigcap_{k} \overline{c o}\left\{u_{n}(t): n \geqq k\right\} \cap F\left(U_{t}\right), y \in F\left(U_{t}\right)$ and $\varepsilon>0$. If $y=z$, this lemma is obvious. So, let $y \neq z$. For any $n \geqq 0$, define a unique element $y_{n}$ such that $y_{n} \in\left[y, u_{n}(t)\right]$ and $\left|y_{n}-z\right|=\min \left\{|u-z|: u \in\left[y, u_{n}(t)\right]\right\}$.

Then, since $y \neq z$, by Lemma 2 we have $y_{n} \neq y$. There exists $c>0$ such that for any $n \geqq 0$ there is $n^{\prime} \geqq n$ with $\left|y_{n^{\prime}}-y\right| \geqq c$. Setting

$$
y_{n^{\prime}}=a_{n^{\prime}} u_{n^{\prime}}(t)+\left(1-a_{n^{\prime}}\right) y, \quad 0 \leqq a_{n^{\prime}} \leqq 1 .
$$

We also obtain $c_{0}>0$ so small that $a_{n^{\prime}} \geqq c_{0}$. In fact, since

$$
\begin{aligned}
c \leqq\left|y_{n^{\prime}}-y\right| & =a_{n^{\prime}}\left|u_{n^{\prime}}(t)-y\right| \\
& \leqq a_{n^{\prime}}|U(t, 0) x-y|,
\end{aligned}
$$

we may put $c_{0}=c /|U(t, 0) x-y|$. Since the limit of $\left|u_{n}(t)-y\right|$ exists, putting $k=\lim _{n \rightarrow \infty}\left|u_{n}(t)-y\right|$, we have $k>0$. If not, we have $u_{n}(t) \rightarrow y$ and hence $y_{n} \rightarrow y$, which contradictions $y_{n} \not y$. Let $r$ be a positive number such that $\varepsilon>r$ and $k>2 r$. Choose $a>0$ so small that

$$
(R+a)\left(1-\delta\left(\frac{c_{0} r}{R+a}\right)\right)<R,
$$

where $\delta$ is the modulus of convexity of the norm and $R=|z-y|$. By Lemma 1 , there exists $n_{0} \geqq 0$ such that

$$
\mid U(m T+t, t)\left(c_{0} u_{n}(t)+\left(1-c_{0}\right) y\right)-\left(c_{0} U(m T+t, t) u_{n}(t)+\left(1-c_{0}\right) y \mid<a\right.
$$

for all $n \geqq n_{0}$ and $m \geqq 0$. Fix $n^{\prime} \geqq 0$ with $n^{\prime} \geqq n_{0}$ and $\left|u_{m+n^{\prime}}(t)-y\right| \geqq 2 r$ and $\left|u_{m+n^{\prime}}(t)-U(m T+t, t) u_{n^{\prime}}(t)\right|<r$ for all $m \geqq 0$. Then since

Hence

$$
c_{0} u_{n^{\prime}}(t)+\left(1-c_{0}\right) y \in\left[y, a_{n^{\prime}} u_{n^{\prime}}(t)+\left(1-a_{n^{\prime}}\right) y\right]=\left[y, y_{n^{\prime}}\right] \text {. }
$$

$$
\begin{aligned}
\left|c_{0} u_{n^{\prime}}(t)+\left(1-c_{0}\right) y-z\right| & \leqq \max \left\{|z-y|,\left|z-y_{n^{\prime}}\right|\right\} \\
& =|z-y|=r .
\end{aligned}
$$

By using (2), we obtain

$$
\begin{aligned}
& \left|c_{0} U(m T+t, t) u_{n^{\prime}}(t)+\left(1-c_{0}\right) y-z\right| \\
& \leqq \\
& \quad+\left(1-c_{0}\right) y-U(m T+t, t)\left(c_{0} u_{n^{\prime}}(t)+\left(1-c_{0}\right) y\right)-z|+| c_{0} U(m T+t, t)\left(c_{0} u_{n^{\prime}}(t)+\left(1-c_{0}\right) y \mid\right.
\end{aligned}
$$




$$
\begin{aligned}
& \leqq\left|U(m T+t, t)\left(c_{0} u_{n^{\prime}}(t)+\left(1-c_{0}\right) y\right)-z\right|+a \\
& \leqq\left|c_{0} u_{n^{\prime}}(t)+\left(1-c_{0}\right) y-z\right|+a \\
& \leqq R+a
\end{aligned}
$$

for all $m \geqq 0$. On the other hand, since $|y-z|=R<R+a$ and

$$
\begin{aligned}
& \left|c_{0} U(m T+t, t) u_{n^{\prime}}(t)+\left(1-c_{0}\right) y-y\right| \\
& \quad=c_{0}\left|U(m T+t, t) u_{n^{\prime}}(t)-y\right| \\
& \quad \geqq c_{0}\left(\left|u_{m+n^{\prime}}(t)-y\right|-\left|u_{m+n^{\prime}}(t)-U(m T+t, t) u_{n^{\prime}}(t)\right|\right) \\
& \quad \geqq c_{0}\left(\left|u_{m+n^{\prime}}(t)-y\right|-r\right) \\
& \quad \geqq c_{0} r
\end{aligned}
$$

for all $m \geqq 0$. By uniform convexity, we have

$$
\begin{aligned}
& \left|\frac{1}{2}\left(\left(c_{0} U(m T+t, t) u_{n^{\prime}}(t)+\left(1-c_{0}\right) y-z\right)+(y-z)\right)\right| \\
& \quad \leqq(R+a)\left(1-\delta\left(\frac{c_{0} r}{R+a}\right)\right)<R
\end{aligned}
$$

for all $m \geqq 0$, and hence

$$
\left|\frac{c_{0}}{2} U(m T+t, t) u_{n^{\prime}}(t)+\left(1-\frac{c_{0}}{2}\right) y-z\right|<R
$$

for all $m \geqq 0$. This implies that if $u_{m}=\left(c_{0} / 2\right) U(m T+t, t) u_{n^{\prime}}(t)+\left(1-\left(c_{0} / 2\right)\right) y$, then $\left|u_{m}+\alpha\left(y-u_{m}\right)-z\right| \geqq|y-z|$ for all $\alpha \geqq 1$. By Theorem 2.5 in [4], we have

$$
\left\langle u_{m}+\alpha\left(y-u_{m}\right)-y, J(y-z)\right\rangle \geqq 0
$$

and hence $\left\langle u_{m}-y, J(y-z)\right\rangle \leqq 0$. Then $\left\langle U(m T+t, t) u_{n^{\prime}}(t)-y, J(y-z)\right\rangle \leqq 0$. Therefore

$$
\begin{aligned}
& \left\langle u_{m+n^{\prime}}(t)-y, J(y-z)\right\rangle \\
& \leqq \\
& \quad\left|u_{m+n^{\prime}}(t)-U(m T+t, t) u_{n^{\prime}}(t) \| y-z\right| \\
& \quad+\left\langle U(m T+t, t) u_{n^{\prime}}(t)-y, J(y-z)\right\rangle \\
& \leqq \varepsilon|y-z|
\end{aligned}
$$

for all $m \geqq 0$. This completes the proof.

\section{Theorems.}

THEOREM 1. Let $X$ be a uniformly convex Banach space with a Fréchet differentiable norm and $u$ be an almost semitrajectory of $U$. If $F\left(U_{t}\right) \neq \phi$, then 
for any $n \in N$, the set

$$
\bigcap_{k} \overline{c o}\left\{u_{n}(t): n \geqq k\right\} \cap F\left(U_{t}\right)
$$

consists of at most one point.

Proof. For any $n \in N$, let $y, z \in \bigcap_{k} \overline{c o}\left\{u_{n}(t): n \geqq k\right\} \cap F\left(U_{t}\right)$. Then, since $((y+z) / 2) \in F\left(U_{t}\right)$, it follows from Lemma 3 that for any $\varepsilon>0$, there exists $n_{0} \geqq 0$ such that

$$
\begin{aligned}
& \left\langle u_{n}(t)-\frac{y+z}{2}, J\left(\frac{y+z}{2}-z\right)\right\rangle \\
& \quad \leqq \varepsilon\left|\frac{y+z}{2}-z\right|
\end{aligned}
$$

for all $n \geqq n_{0}$. Since $y \in \overline{c o}\left\{u_{n}(t): n \geqq k\right\}$, we have

$$
\left\langle y-\frac{y+z}{2}, J\left(\frac{y+z}{2}-z\right)\right\rangle \leqq \varepsilon\left|\frac{y+z}{2}-z\right|
$$

and hence $\langle y-z, J(y-z)\rangle \leqq 2|y-z|$. Thus $|y-z| \leqq 2 \varepsilon$. Since $\varepsilon$ is arbitrary, consequently $y=z$.

THEOREM 2. Let $X$ be a uniformly convex Banach space with a Fréchet differentiable norm and $u$ be an almost semitrajectory of $U$. If $F\left(U_{t}\right) \neq \phi$ and $\omega\left(u_{n}(t)\right) \subset F\left(U_{t}\right)$, then the sequence $\left\{u_{n}(t): n \in N\right\}$ converges weakly to some $z \in$ $F\left(U_{t}\right)$, where $\omega\left(u_{n}(t)\right)=\left\{y \in X: u_{n_{i}}(t) \rightarrow y\right.$ with $n_{i} \rightarrow \infty$ as $\left.n \rightarrow \infty\right\}$.

Proof. Since $F\left(U_{t}\right) \neq \phi .\left\{u_{n}(t): n \in N\right\}$ bounded. So, the sequence $\left\{u_{n}(t)\right\}$ must contain a subsequence $\left\{u_{n_{i}}(t)\right\}$ of $\left\{u_{n}(t)\right\}$ which converges weakly to some $z \in C_{t}=D(A)$. Since $\omega\left(u_{n}(t)\right) \subset F\left(U_{t}\right)$ and $z \in \bigcap_{k} \overline{c o}\left\{u_{n}(t): n \geqq k\right\}$, we obtain

$$
z \in \bigcap_{\boldsymbol{k}} \overline{c o}\left\{u_{n}(t): n \geqq k\right\} \cap F\left(U_{t}\right) .
$$

Therefore, it follows from Theorem 1 that $\left\{u_{n}(t): n \in N\right\}$ converges weakly to $z \in F\left(U_{t}\right)$.

THEOREM 3. Let $X$ be a uniformly convex Banach space and $F\left(U_{t}\right) \neq \phi$. Let $P$ be the metric projection of $X$ onto $F\left(U_{t}\right)$. Then the strong $\lim _{n \rightarrow \infty} u_{n}(t)$ exists and $\lim _{n \rightarrow \infty} P u_{n}(t)=z_{0}$, where $z_{0}$ is a unique element of $F\left(U_{t}\right)$ such that

$$
\lim _{n \rightarrow \infty}\left|u_{n}(t)-z_{0}\right|=\min \left\{\lim _{n \rightarrow \infty}\left|u_{n}(t)-z\right|: z \in F\left(U_{t}\right)\right\} .
$$

Proof. Since $F\left(U_{t}\right) \neq \phi$, we know that $\left\{u_{n}(t): n \in N\right\}$ is bounded and $\lim _{n \rightarrow \infty}\left|u_{n}(t)-z\right|=\rho(z)$ exists for each $z \in F\left(U_{t}\right)$. Let $R=\min \left\{\rho(z): z \in F\left(U_{t}\right)\right\}$. Then, 
since $\rho$ is convex and continuous on $F\left(U_{t}\right)$ and $\rho(z) \rightarrow \infty$ as $z \rightarrow \infty$, there exists $z_{0} \in F\left(U_{t}\right)$ such that $\rho\left(z_{0}\right)=R$; see $[2: \mathrm{p} 79]$. On the other hand, since $\mid u_{n}(t)-$ $P u_{n}(t)|\leqq| u_{n}(t)-y \mid$ for all $n \in N$ and $y \in F\left(U_{t}\right)$, we have

$$
\lim _{n \rightarrow \infty}\left|u_{n}(t)-P u_{n}(t)\right| \leqq R
$$

Suppose that $\lim _{n \rightarrow \infty}\left|u_{n}(t)-P u_{n}(t)\right|<R$. Then we can choose $\varepsilon>0$ and $n_{0} \geqq 0$ such that

$$
\left|u_{n}(t)-P u_{n}(t)\right|<R-\varepsilon \quad \text { for all } n \geqq n_{0} .
$$

We observe that

$$
\left|u_{n+1}(t)-P u_{n+1}(t)\right| \leqq\left|u_{n}(t)-P u_{n}(t)\right| \quad \text { for all } n \geqq 0 .
$$

Thus, there exists $n_{0} \geqq 0$ such that

$$
\begin{aligned}
\left|u_{n+1}(t)-P u_{n+1}(t)\right| & \leqq\left|u_{n}(t)-P u_{n}(t)\right| \\
& <R-\varepsilon
\end{aligned}
$$

for all $n \geqq n_{0}$. Thus $\lim _{n \rightarrow \infty}\left|u_{n}(t)-P u_{n}(t)\right|<R$. This is a contradiction. So we conclude that

$$
\lim _{n \rightarrow \infty}\left|u_{n}(t)-P u_{n}(t)\right|=R .
$$

We claim that $\lim _{n \rightarrow \infty} P u_{n}(t)=z_{0}$. If not, then we have $\left|P u_{n}(t)-z_{0}\right| \geqq \varepsilon$ for some $\varepsilon>0$ and $n \rightarrow \infty$. Let $\delta$ denote the modulus of convexity of $X$. There is a positive a such that

$$
(R+a)\left(1-\delta\left(\frac{a}{R+a}\right)\right)=R_{1}<R .
$$

We also have $\left|u_{n}(t)-P u_{n}(t)\right| \leqq R+a$ and $\left|u_{n}(t)-z_{0}\right| \leqq R+a$ for all large enough $n$. Therefore

$$
\begin{aligned}
\left|u_{n}(t)-\frac{P u_{n}(t)+z_{0}}{2}\right| & \leqq(R+a)\left(1-\delta\left(\frac{\varepsilon}{R+a}\right)\right) \\
& =R_{1}<R-\varepsilon .
\end{aligned}
$$

Since the points $w_{n}=\left(P u_{n}(t)+z_{0}\right) / 2$ belong to $F\left(U_{0}\right)$, also, there is $n_{0} \geqq 0$ such that

$$
\begin{aligned}
\left|u_{n+1}(t)-w_{n+1}(t)\right| & \leqq\left|u_{n}(t)-w_{n}(t)\right| \\
& <R-\varepsilon<R
\end{aligned}
$$

for all $n \geqq n_{0}$. Thus we obtain $\rho\left(w_{n}\right)<R$. This is a contradiction. Therefore $\lim _{n \rightarrow \infty} P u_{n}(t)=z_{0}$. Consequently, it follows that an element $z_{0} \in F\left(U_{0}\right)$ with $\rho\left(z_{0}\right)=$ $\min \left\{\rho(z): z \in F\left(U_{t}\right)\right\}$ is unique. 


\section{Remarks.}

Fix $t \in[0, T]$, let $G=\{0,1,2, \cdots\}$ and $S(n)=U_{t}^{n}, n \in G$ where $U_{t}=U(T+t, t)$ : $\overline{D(A)} \rightarrow \overline{D(A)}$. Then, $\{S(n): n \in G\}$ is nonexpansive semigroup on $\overline{D(A)}$ and $F(S)$ $=F\left(U_{t}\right) \neq \phi$.

Next, we define $u(n)=u_{n}(t)=U(n T+t, 0) x$, fix $t \in[0, T]$, then $u: G \rightarrow X$ is an almost-orbit of $\{S(n)\}$.

In fact,

$$
\begin{aligned}
u(n) & =u_{n}(t) \\
& =U(n T+t, 0) x \\
& =U(n T+t, t) U(t, 0) x \\
& =U(n T+t, t) z, z=U(t, 0) x \\
& =U_{t}^{n} z=S(n) z .
\end{aligned}
$$

Thus we have

$$
\begin{aligned}
|u(n+m)-S(n) u(m)| & =|S(n+m) z-S(n) S(m) z| \\
& =|S(n+m) z-S(n+m) z|=0 .
\end{aligned}
$$

Hence $u: G \rightarrow X$ is an almost-orbit of $\{S(n)\}$. Therefore, by [5]

THEOREM 1-3.

$$
\bigcap_{m \geqq 0} \overline{c o}\{u(n): n \geqq m\} \cap F\left(U_{t}\right)
$$

consists of at most one point.

Acknowledgements. The author wishes to express his deep appreciation to Professor W. Takahashi for his many stimulating conversation and to Professor $K$. Kobayashi for his many helpful suggestions.

\section{REFERENCES}

[1] V. BARBU, Nonlinear semıgroup and differential equations in Banach space, Noordhoff International Publ., Leyden, 1976.

[2] V. Barbu and Th. Precupanu, Convexity and optization in Banach spaces, Editura Academiei R.S.T., Bucuresti, 1978.

[3] R.E. BRUCK, Construction of periodic solutions of periodic contraction systems from bounded solutions, Proceeding of Symposia in Pure Mathematics 45 (1986), 227-235.

[4] F.R. Deutsch and P.H. Maserick, Application of the Hahn-Banach theorem in approximation theory, SIAM Rev., 9 (1967), 516-530.

[5] C.W. Groetsch, A note on segmenting Mann iterates, J. Math. Anal. Appl., 40 
(1972), 369-372.

[6] A.T. LAU AND W. TAKAHASHI, Weak convergence and nonlinear ergodic theorems for reversible semigroup of nonexpansive mappings, Pacific Journal of Mathematics, 126 (1987), 277-294.

[7] W. TAKAHASHI AND J.Y. PARK, On the asymptotic behavior of almost-orbit of commutative semigroups in Banach space, Nonlinear and Convex Analysis, 107 (1987), 271-293.

[8] K. KoBAYASHI, Asymptotic behavior of periodic nonexpansive evolution operations in uniformly convex Banach space, Hiroshima Math. J., 16 (1987), 531-537.

Department of Mathematics

Pusan National University

Dongrae, Pusan

REPUblic OF KoREa 607 